\title{
GLP-1 receptor agonist on cardiovascular complications of diabetes mellitus
}

\author{
FENGJUN LIU ${ }^{1}$ and YANHUA KONG ${ }^{2}$ \\ Departments of ${ }^{1}$ Cardiovascular Medicine (II) and ${ }^{2}$ Internal Medicine, \\ Tengzhou Central People's Hospital, Tengzhou, Shandong 277500, P.R. China
}

Received August 6, 2019; Accepted December 3, 2019

DOI: $10.3892 /$ etm.2020.8439

\begin{abstract}
Effects of glucagon-like peptide-1 (GLP-1) receptor agonist on cardiovascular complications of diabetes mellitus (DM) were investigated. In total, 132 DM patients treated in Tengzhou Central People's Hospital from April 2013 to September 2016 were included. Of these, 71 cases treated with basic drugs plus GLP-1 were the research group, and 61 cases treated with glipizide controlled release tablets the control group. The improvement of clinical efficacy of patients in the two groups after treatment was observed. The concentrations of FPG, HbAlc, TC, LDL-C, and HDL-C in serum of patients in the two groups before and after treatment were compared, and the incidence rate of cardiovascular disease complications of diabetes was recorded. Expression of FPG, HbAlc, TC, LDL-C, and HDL-C of patients in the two groups were further detected. ROC curve was drawn to analyze its predictive value. In terms of markedly effective treatment rate and overall effective rate, the research group was significantly better than the control group $(\mathrm{P}<0.05)$. After treatment, the concentrations of FPG, HbAlc, TC, LDL-C, and HDL-C in serum of patients in the research group were significantly lower than those in the control group $(\mathrm{P}<0.05)$. The incidence rate of cardiovascular diseases and residual vascular risks in the research group were significantly higher than those in the control group $(\mathrm{P}<0.05)$. After treatment, the AUC of FPG, HbAlc, TC, LDL-C, and HDL-C in serum for predicting cardiovascular complications in DM patients were, respectively, $0.742,0.780,0.737,0.726$, and 0.721 . In conclusion, GLP-1 receptor agonist can improve the clinical efficacy of patients. Through ROC curve, FPG, HbAlc, TC, LDL-C and HDL-C can be used as predictors of cardiovascular complications in DM patients, which has high clinical value.
\end{abstract}

Correspondence to: Dr Fengjun Liu, Department of Cardiovascular Medicine (II), Tengzhou Central People's Hospital, 181 Xingtan Road, Tengzhou, Shandong 277500, P.R. China

E-mail: pfy0on@163.com

Key words: GLP-1 receptor agonist, diabetes mellitus, cardiovascular disease complications

\section{Introduction}

Diabetes mellitus (DM) is a very common metabolic disorder with a very high morbidity in the world (1). DM is a group of metabolic diseases characterized by hyperglycemia caused by insulin secretion deficiency, insulin action, or both. Chronic hyperglycemia of DM is associated with long-term damage, dysfunction, and failure of different organs, especially eyes, kidneys, nerves, heart, and blood vessels (2). DM is the disease with the highest morbidity in the world at present. With the progress of society and the improvement of people's quality of life, the morbidity tend to be increasing (3). It was reported that the global DM patients will reach $25.6 \%$ in 2015 (4). DM causes various complications, such as cardiovascular and cerebrovascular diseases, nervous system diseases, and kidney diseases. The disease deteriorates without timely treatment, malignant tumor diseases will be directly caused. DM is defined by the elevation of blood glucose markers and is a major risk factor for cardiovascular diseases, which is the most common cause of death for DM patients (5).

Reducing cardiovascular disease burden of DM patients is an important clinical task. Priority should be given to reducing premature death, improving quality of life, reducing individual and economic burden of related diseases (6). Glucagon-like peptide-1 (GLP-1) is a physiological incretin hormone that is released after the intake of nutrients from the lower digestive tract and stimulates insulin secretion at elevated blood glucose concentrations (7). GLP-1 can effectively stimulate insulin, inhibit glucagon secretion, inhibit gastric emptying, and reduce appetite and food intake (8). However, whether GLP-1 receptor agonist can affect cardiovascular complications in DM patients still needs further research. Therefore, this investigation was carried out to provide reference for future clinical practice on the concentration of blood sugar and blood lipid before and after DM treatment, and the predictive value of blood sugar and blood lipid concentration after DM treatment on cardiovascular disease complications of DM patients.

\section{Patients and methods}

General data. This study includes 132 DM patients who were treated in Tengzhou Central People's Hospital (Tengzhou, China) from April 2013 to September 2016. In the research group, basic drugs plus GLP-1 were used. Patients in the 
research group included 35 males and 36 females, aged 33-65 years, with a mean age of $45.3 \pm 8.2$. Sixty-one cases with glipizide controlled release tablets were in the control group, including 36 males and 25 females, aged 35-68 years, with a mean age of $46.7 \pm 9.5$. This study was approved by the Medical Ethics Committee of Tengzhou Central People's Hospital.

Inclusion and exclusion criteria. Inclusion criteria: Patients were diagnosed and treated in Tengzhou Central People's Hospital; with complete clinical data, aged 30-70 years, able to cooperate with the investigation, and no allergy to test drugs. There are no other serious organ diseases affecting the study, and the informed consent was signed by the patients or family members.

Exclusion criteria: Patients who died in the course of treatment; combined with other tumors; combined with other cardiovascular and cerebrovascular diseases, physical disability, pregnancy; combined with other autoimmune diseases; combined with other chronic diseases, transfer, mental diseases, and language dysfunction, as well as diseases affecting the results of this study.

Treatment plan for patients. The control group was treated with conventional drugs. The patients took glipizide controlled release tablets (Beijing Honglin Pharmaceutical Co., Ltd., SFDA approval no. H20084634) orally, with an initial dose of $5 \mathrm{mg} /$ time and 1 time/day, and then the dose was adjusted according to the results of blood glucose monitoring, but $\leq 20 \mathrm{mg} / \mathrm{day}$, for 4 consecutive months. The research group was given exenatide injection treatment (Guangzhou UWA Technology Co., Ltd., Art. no. 22-197, at $10 \mu \mathrm{g}$. Dosage scale injection pen: $0.25 \mathrm{mg} / \mathrm{ml}, 2.4 \mathrm{ml} / \mathrm{branch}$, a single injection dose of $10 \mu \mathrm{g}$, including 60 injections), subcutaneous injection 2 times/day. The first 3 weeks were the lead-in period, on the basis of the above treatment, the patient was injected subcutaneously with $1 \mathrm{ml}$ of normal saline. From the 4 th to the 7 th week, patients were treated with GLP-1 receptor agonist (H20090382, Hangzhou Haoxin Biotechnology Co., Ltd., Art. no. HYP0014-1, at $10 \mu \mathrm{g}$ dose scale injection pen: $0.25 \mathrm{mg} / \mathrm{ml}, 2.4 \mathrm{ml} / \mathrm{branch}, 10 \mu \mathrm{g}$ for single injection, 60 injections), $10 \mu \mathrm{g} /$ time, 2 times/day. Patients were injected with GLP-1 receptor agonist from the 8 th to 15 th weeks, $10 \mu \mathrm{g} /$ time, 2 times/day for continuous treatment for 4 months.

Efficacy assessment. The criteria for clinical efficacy: markedly effective: clinical signs, symptoms completely disappeared or significantly relieved; effective: comprehensive symptoms have some relief; invalid: no change in clinical symptoms and signs. The criteria for cardiac autonomic function: markedly effective: cardiac autonomic function returned to normal or significantly improved; effective: cardiac autonomic function improved; invalid: no change in cardiac autonomic function.

Detection methods. Venous blood $(5 \mathrm{ml})$ was drawn from patients in the two groups before and after treatment, respectively. The venous blood was quiescent for $30 \mathrm{~min}$ and centrifuged at $1,500 \mathrm{xg}$ at $24^{\circ} \mathrm{C}$ for $10 \mathrm{~min}$. The blood glucose function (fasting blood glucose FPG, glycosylated hemoglobin
HbAlc) and blood lipid function (serum total cholesterol TC, low density lipoprotein cholesterol LDL-C, high density lipoprotein cholesterol HDL-C) were detected by a full automatic biochemical analyzer (Jiaozuo Lufeifan Biotechnology Co., Ltd., Art. no. LFF-LC-1781).

Observation indicators. Indicators to be observed: The improvement of clinical efficacy of patients in the two groups after treatment were observed; the concentrations of FPG, HbAlc, TC, LDL-C, and HDL-C in serum of patients in the two groups before and after treatment were compared; and the incidence rate of cardiovascular disease complications of diabetic were recorded.

Secondary observation indicators: The predictive value of concentrations of FPG, HbAlc, TC, LDL-C, and HDL-C on cardiovascular disease was observed.

Statistical methods. In this study, SPSS 20.0 software was used to carry out statistical analysis on the collected data, GraphPad 7 software was used to draw the required illustrations and K-S test was used to analyze the distribution of dose data. Normal distribution data were expressed by mean \pm standard deviation (mean $\pm \mathrm{SD}$ ). Inter-group comparison was conducted by independent-samples t-test, and intra-group comparison was conducted by paired t-test. Counting data, utilization (\%), were expressed by Chi-square $\left(\chi^{2}\right)$ test. The predictive value of FPG, HbAlc, TC, LDL-C, and HDL-C on cardiovascular diseases of $\mathrm{DM}$ patients after treatment was plotted by ROC (receiver operating characteristic); $\mathrm{P}<0.05$ was considered to indicate a statistically significant difference.

\section{Results}

Basic clinical data of patients. Age, sex, BMI, marital status, ethnicity, place of residence, smoking and drinking history, and movement condition in the clinical data of the research group and the control group were not significantly different $(\mathrm{P}>0.05)$, as shown in Table I.

Improvement of clinical efficacy of patients in the two groups after treatment. Total of 38 cases $(53.52 \%)$ were markedly effective, and 24 cases $(33.80 \%)$ were effective in the research group; 22 cases $(36.07 \%)$ were markedly effective and 21 cases $(34.43 \%)$ were effective in the control group. In terms of marked effect, the research group was significantly higher than the control group $(\mathrm{P}<0.05)$, while in terms of effectiveness, the two groups had no statistical significance $(\mathrm{P}>0.05)$. The effective treatment rate in the research group $(87.32 \%)$ was significantly higher than the control group $(70.49 \%) . \mathrm{P}<0.05$, indicates a statistically significant difference (Table II).

Comparison of concentrations of FPG, HbAlc, TC, LDL-C, and HDL-C in serum of patients between the two groups before and after treatment. The concentrations of FPG, HbAlc, TC, LDL-C, and HDL-C in the research group were, respectively, $11.54 \pm 1.28 \mathrm{mmol} / 1,11.03 \pm 1.18 \%, 5.48 \pm 1.27$, $4.18 \pm 1.19$ and $1.68 \pm 0.43 \mathrm{mmol} / \mathrm{l}$ before treatment. After treatment, the concentrations of FPG, HbAlc, TC, LDL-C, 
Table I. Clinical data of patients [n (\%)].

\begin{tabular}{|c|c|c|c|c|}
\hline Item & Research group (71) & Control group (61) & $\chi^{2}$ or $\mathrm{t}$ & P-value \\
\hline Age & $45.3 \pm 8.2$ & $46.7 \pm 9.5$ & 0.909 & 0.365 \\
\hline Sex & & & 1.247 & 0.264 \\
\hline Male & $35(49.30)$ & $36(59.02)$ & & \\
\hline Female & $36(50.70)$ & $25(40.98)$ & & \\
\hline $\operatorname{BMI}\left(\mathrm{kg} / \mathrm{m}^{2}\right)$ & $25.26 \pm 0.37$ & $25.21 \pm 0.25$ & 0.894 & 0.373 \\
\hline Marital status & & & 0.356 & 0.551 \\
\hline Married & $63(88.73)$ & $52(85.25)$ & & \\
\hline Unmarried & $8(11.27)$ & $9(14.75)$ & & \\
\hline Ethnicity & & & 0.382 & 0.536 \\
\hline Han & $61(85.92)$ & $50(81.97)$ & & \\
\hline Minority & $10(14.08)$ & $11(18.03)$ & & \\
\hline Place of residence & & & 0.115 & 0.735 \\
\hline City & $41(57.75)$ & 37 (60.66) & & \\
\hline Countryside & $30(42.25)$ & $24(39.34)$ & & \\
\hline Smoking history & & & 0.065 & 0.799 \\
\hline Yes & $38(53.52)$ & $34(55.74)$ & & \\
\hline No & $33(46.48)$ & $27(44.26)$ & & \\
\hline Drinking history & & & 1.988 & 0.159 \\
\hline Yes & $32(45.07)$ & $35(57.38)$ & & \\
\hline No & $39(54.93)$ & $26(42.62)$ & & \\
\hline Exercise habits & & & 0.131 & 0.717 \\
\hline Yes & $35(49.30)$ & $32(52.46)$ & & \\
\hline No & $36(50.70)$ & $29(47.54)$ & & \\
\hline
\end{tabular}

Table II. Efficacy of patients in the two groups.

\begin{tabular}{lccccc}
\hline & & \multicolumn{3}{c}{ Efficacy [n (\%)] } & \\
\cline { 3 - 4 } Group & Number (n) & Markedly effective & Effective & Ineffective & Effective treatment rate (\%) \\
\hline Research group & 71 & $38(53.52)$ & $24(33.80)$ & $9(12.68)$ & 87.32 \\
Control group & 61 & $22(36.07)$ & $21(34.43)$ & $18(29.51)$ & 70.49 \\
$\chi^{2}$ & & 4.032 & 0.006 & 5.713 & 5.713 \\
P-value & 0.045 & 0.940 & 0.017 & 0.017 \\
\hline
\end{tabular}

and HDL-C in the research group were, respectively, $6.13 \pm 0.35 \mathrm{mmol} / 1,7.15 \pm 0.34 \%, 3.93 \pm 0.62,1.95 \pm 0.84$ and $0.75 \pm 0.42 \mathrm{mmol} / \mathrm{l}$. The concentrations of FPG, HbAlc, TC, LDL-C, and HDL-C in the control group were, respectively, $11.62 \pm 1.34,11.53 \pm 0.82 \%, 5.53 \pm 1.31,3.06 \pm 0.82$ and $1.30 \pm 0.67 \mathrm{mmol} / 1$ before treatment. After treatment, the concentrations of FPG, HbAlc, TC, LDL-C, and HDL-C in the control group were, respectively, $6.57 \pm 0.63 \mathrm{mmol} / \mathrm{l}$, $7.62 \pm 0.56 \%, 4.95 \pm 0.92,2.68 \pm 0.73$ and $1.08 \pm 0.57 \mathrm{mmol} / 1$. There was no significant difference of patients between the two groups before treatment, $P>0.05$. After treatment, the indicators of patients in the research group were significantly lower than those in the control group. $\mathrm{P}<0.05$, as shown in Table III and Fig. 1.
Incidence rate of cardiovascular diseases in DM patients. Comparing the incidence rate of cardiovascular diseases and residual vascular risks of patients between the two groups, the incidence rate of cardiovascular diseases and residual vascular risks in the research group were significantly lower than those in the control group. $\mathrm{P}<0.05$ (Table IV).

The predictive value of the concentration of FPG, HbAlc, $T C, L D L-C$, and HDL-C on cardiovascular diseases in DM patients after treatment. Patients were divided into the occurrence group and the non-occurrence group. The expression of FPG, HbAlc, TC, LDL-C, and HDL-C in the two groups was further detected and found to be different. The ROC curves were drawn, showing that the AUC of FPG, 
Table III. Comparison of the two groups of patients before and after treatment.

\begin{tabular}{|c|c|c|c|c|}
\hline \multirow[b]{2}{*}{ Indicator } & \multicolumn{2}{|c|}{ Research group $(n=71)$} & \multicolumn{2}{|c|}{ Control group $(n=61)$} \\
\hline & Before treatment & After treatment & Before treatment & After treatment \\
\hline FPG (mmol/l) & $11.54 \pm 1.28$ & $6.13 \pm 0.35^{\mathrm{a}}$ & $11.62 \pm 1.34^{\mathrm{b}}$ & $6.57 \pm 0.63^{\mathrm{a}, \mathrm{c}}$ \\
\hline HbAlc (\%) & $11.03 \pm 1.18$ & $7.15 \pm 0.34^{\mathrm{a}}$ & $11.53 \pm 0.82^{\mathrm{b}}$ & $7.62 \pm 0.56^{\mathrm{a}, \mathrm{c}}$ \\
\hline $\mathrm{TC}(\mathrm{mmol} / \mathrm{l})$ & $5.48 \pm 1.27$ & $3.93 \pm 0.62^{\mathrm{a}}$ & $5.53 \pm 1.31^{\mathrm{b}}$ & $4.95 \pm 0.92^{\mathrm{a}, \mathrm{c}}$ \\
\hline LDL-C (mmol/l) & $4.18 \pm 1.19$ & $1.95 \pm 0.84^{\mathrm{a}}$ & $3.06 \pm 0.82^{b}$ & $2.68 \pm 0.73^{\mathrm{a}, \mathrm{c}}$ \\
\hline HDL-C (mmol/l) & $1.68 \pm 0.43$ & $0.75 \pm 0.42^{\mathrm{a}}$ & $1.30 \pm 0.67^{b}$ & $1.08 \pm 0.57^{\mathrm{a}, \mathrm{c}}$ \\
\hline $\mathrm{F}$ & $1,068.000$ & $1,724.000$ & $1,312.000$ & $1,404.000$ \\
\hline P-value & 0.001 & 0.001 & 0.001 & 0.001 \\
\hline
\end{tabular}

${ }^{\mathrm{a}} \mathrm{P}<0.05$, compared with before treatment in the same group; ${ }^{\mathrm{b}} \mathrm{P}>0.05$, compared with the research group before treatment; ${ }^{\mathrm{c}} \mathrm{P}>0.05$, compared with the research group after treatment.
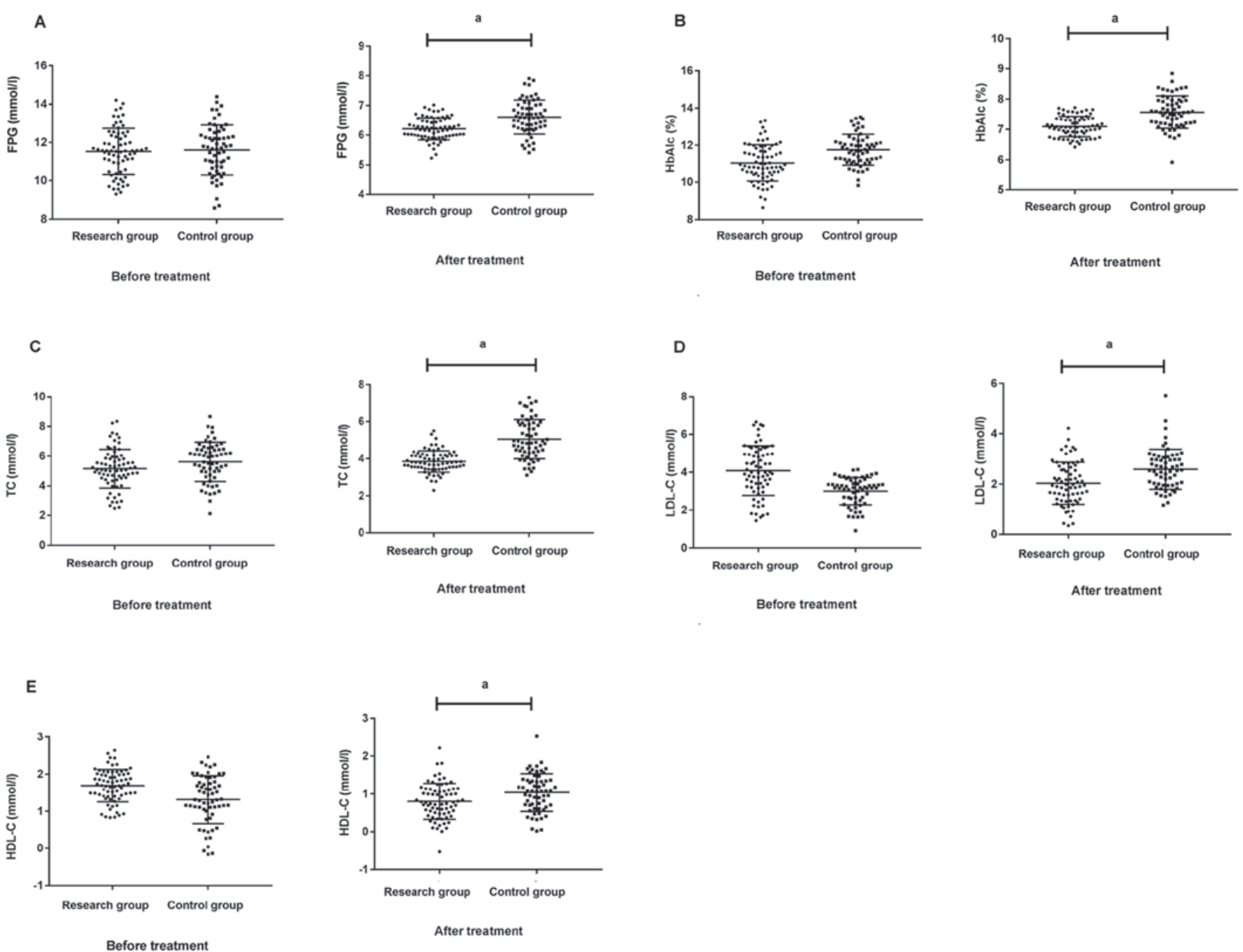

Figure 1. Comparison of concentrations of FPG (A), HbAlc (B), TC (C), LDL-C (D), and HDL-C (E) in serum of patients in the two groups before treatment and after treatment. There was no significant difference in patients between the two groups before treatment, $P>0.05$. After treatment, the indicators of patients in the research group were significantly lower than those in the control group $(\mathrm{P}<0.05)$. a, indicates a difference at $\mathrm{P}<0.05$.

HbAlc, TC, LDL-C and HDL-C were 0.742, 0.780, 0.737, 0.726 , and 0.721 , respectively, which had good prediction value (Table V and Fig. 2).

\section{Discussion}

$\mathrm{DM}$ is defined as a group of metabolic diseases, characterized 
Table IV. Comparison of incidence rate of cardiovascular disease and residual vascular risks [(n $(\%)]$.

\begin{tabular}{lcc}
\hline Group & Incidence rate of cardiovascular diseases & Incidence rate of residual vascular risks \\
\hline Research group $(\mathrm{n}=71)$ & $4(5.63)$ & 1 \\
Control group $(\mathrm{n}=61)$ & $10(16.13)$ & $7(1.41)$ \\
$\chi^{2}$ & 3.871 & 5.840 \\
P-value & 0.049 & 0.016 \\
\hline
\end{tabular}

Table V. ROC diagnosis.

\begin{tabular}{|c|c|c|c|c|c|c|}
\hline Indicators & AUC & $95 \% \mathrm{CI}$ & Sensitivity & Specificity & Standard error & Cut-off \\
\hline FPG & 0.742 & $0.654-0.831$ & $73.77 \%$ & $69.01 \%$ & 0.045 & 6.349 \\
\hline HbAlc & 0.780 & $0.701-0.859$ & $60.66 \%$ & $83.10 \%$ & 0.040 & 7.440 \\
\hline $\mathrm{TC}$ & 0.737 & $0.647-0.826$ & $63.93 \%$ & $81.69 \%$ & 0.046 & 4.924 \\
\hline LDL-C & 0.726 & $0.640-0.812$ & $73.77 \%$ & $66.20 \%$ & 0.044 & 2.238 \\
\hline HDL-C & 0.721 & $0.633-0.808$ & $68.58 \%$ & $69.01 \%$ & 0.045 & 1.018 \\
\hline
\end{tabular}

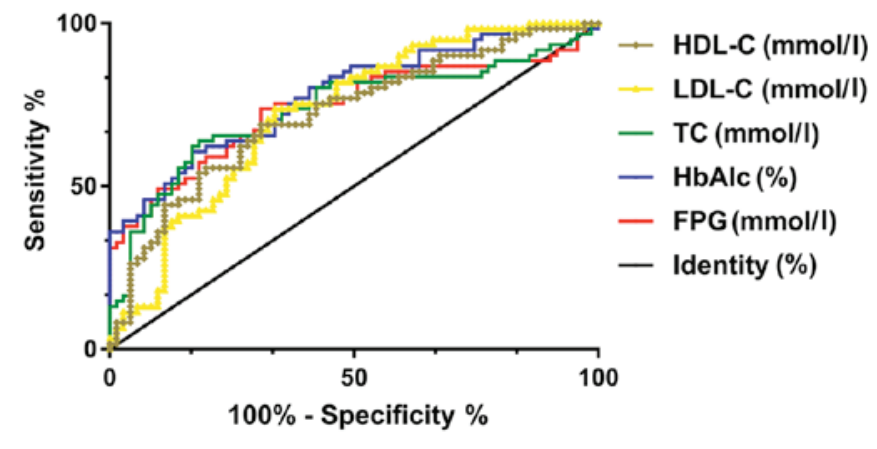

Figure 2. Predictive value of concentrations of FPG, HbAlc, TC, LDL-C, and HDL-C on cardiovascular diseases in DM patients after treatment. ROC curve analysis shows that FPG has a sensitivity of $73.77 \%$ and specificity of $69.01 \%$ for predicting cardiovascular diseases in DM patients when cut-off value is 6.349 . When cut-off value is 7.440 , HbAlc has a sensitivity of $60.66 \%$ and specificity of $83.10 \%$ for predicting cardiovascular disease in DM patients. When the cut-off value is 4.924 , the sensitivity of TC to the predictive value of cardiovascular diseases in DM patients is $63.93 \%$, the specificity is $81.69 \%$, and the AUC is 0.773 . When cut-off value is 2.238 , LDL-C has a sensitivity of $73.77 \%$, specificity of $66.20 \%$, and AUC of 0.726 for predicting cardiovascular disease in DM patients. When cut-off value is 1.108 , the sensitivity and specificity of HDL-C for predicting cardiovascular diseases in DM patients are 68.58 and $69.01 \%$, respectively. DM, diabetes mellitus.

by hyperglycemia caused by insulin secretion deficiency, insulin action, or both (2). In 2014, the global prevalence of DM was $\sim 9 \%$ (9), and nearly 1.3 million people died of DM (10) in 2010. DM is also associated with high morbidity due to a wide range of complications, such as retinopathy, nephropathy, neuropathy, and cardiovascular diseases $(11,12)$. Prevention and management of these complications have become the main aspect of modern DM nursing.

Epidemiological studies show that overweight and obesity are important risk factors for DM, cardiovascular diseases, cancer, and premature death (13). The main risk factor for complications of DM is poor blood glucose control (14). Some studies have shown that chronic hyperglycemia is related to microvascular complications $(15,16)$. Although it has been proved that improving blood sugar control can reduce microvascular complications in DM patients (17), its relationship with macrovascular complications and all-cause mortality is still uncertain. In the study of Nadkarni et al (18), GLP-1's hypoglycemic effect was shown to be dependent on glucose. GLP-1 can reduce blood glucose level only when blood glucose concentration is higher than fasting level. The postprandial blood glucose level decreases with the decrease of GLP-1, and the hypoglycemic effect of GLP-1 is self-terminated. This remarkable glucose-dependent characteristic of GLP-1 leads to a situation that intravenous injection of GLP-1 cannot reduce blood glucose below fasting level. These drugs can protect the heart muscle, improve myocardial infarction and heart failure by regulating blood sugar, blood lipids, blood pressure, and through anti-inflammatory and anti-oxidative stress mechanisms. Because GLP-1 does not produce hypoglycemia, these clinical findings lead to the use of GLP-1 receptor agonist as a new hypoglycemic agent, which can be used to treat DM. Therefore, in this study, DM patients were treated through GLP-1 receptor agonist scheme, and the improvement of clinical efficacy of DM patients was observed, to provide reference for clinical treatment.

In this study, the clinical efficacy of patients in the two groups after treatment was compared. The results showed that the research group was significantly better than the control group in terms of markedly effective treatment rate, while there was no significant difference in effective treatment rate between the two groups. In terms of overall effective rate, the research group was higher than the control group, which shows that GLP-1 receptor agonist scheme can improve the effective treatment rate of patients. At present, the indicators for clinical detection of DM were generally blood glucose function (FPG, HbAlc) and blood lipid 
function (TC, LDL-C, and HDL-C). Although the cellular regulation of insulin secretion is quite clear, little is known about the control of glucagon secretion $(19,20)$. Whether FPG, HbAlc, TC, LDL-C, and HDL-C can be used as predictors of cardiovascular complications in DM patients has not been reported. In this study, the concentrations of FPG, HbAlc, TC, LDL-C, and HDL-C in serum of the research group and the control group before and after treatment were compared, and it was found that there was no difference in the concentrations of FPG, HbAlc, TC, LDL-C, and HDL-C in serum of patients in the two groups before treatment but in serum of the research group after treatment they were significantly lower than those in the control group, which indicated that FPG, HbAlc, TC, LDL-C, and HDL-C were better inhibited by adding GLP-1 receptor agonist. After treatment, the incidence rate of cardiovascular diseases in DM patients was observed, and it was found that the research group was significantly better than the control group in both the incidence rate of cardiovascular diseases and the incidence rate of residual vascular risks, suggesting that GLP-1 receptor agonist therapy can reduce the incidence rate of complications of cardiovascular diseases in DM patients. In a study by Than and Newsome (21), it is indicated that liraglutide and GLP-1 have extremely high sequence homologs, and their activities interact with GLP-1 receptor to greatly increase the synthesis and metabolism of cyclic adenosine monophosphate. Glucose stimulates insulin to accelerate secretion when blood sugar increases, inhibits glucagon secretion, reduces insulin secretion when blood sugar decreases, and maintains normal metabolism of glucagon. Finally, ROC curve analysis was performed, and it was found that the AUC of FPG, HbAlc, TC, LDL-C, and HDL-C in serum after treatment for predicting cardiovascular disease complications in DM patients was respectively $0.742,0.780,0.737,0.726$, and 0.721 , respectively, which has high clinical value.

In the above studies, the efficacy of GLP-1 receptor agonist on DM patients and the predictive value of FPG, HbAlc, TC, LDL-C, and HDL-C in cardiovascular disease complications of DM patients were preliminarily proven. However, further studies need to be carried out for confirmation.

In conclusion, GLP-1 receptor agonist can improve the clinical efficacy of patients. Through ROC analysis, FPG, HbAlc, TC, LDL-C, and HDL-C can be used as predictors of cardiovascular disease complications in DM patients, which has high clinical value.

\section{Acknowledgements}

Not applicable.

\section{Funding}

No funding was received.

\section{Availability of data and materials}

The datasets used and/or analyzed during the present study are available from the corresponding author on reasonable request.

\section{Authors' contributions}

FL conceived and designed the study, and drafted the manuscript. FL and YK collected, analyzed and interpreted the experimental data. YK revised the manuscript for important intellectual content. Both authors read and approved the final manuscript.

\section{Ethics approval and consent to participate}

The study was approved by the Ethics Committee of Tengzhou Central People's Hospital (Tengzhou, China). Signed informed consents were obtained from the patients and/or the guardians.

\section{Patient consent for publication}

Not applicable.

\section{Competing interests}

The authors declare that they have no competing interests.

\section{References}

1. American Diabetes Association: Standards of medical care in diabetes - 2016 abridged for primary care providers. Clin Diabetes 34: 3-21, 2016.

2. American Diabetes Association: Diagnosis and classification of diabetes mellitus. Diabetes Care 33 (Suppl 1): S62-S69, 2010.

3. American Diabetes Association: (2) Classification and diagnosis of diabetes. Diabetes Care 38 (Suppl): S8-S16, 2015.

4. Zinman B, Wanner C, Lachin JM, Fitchett D, Bluhmki E, Hantel S, Mattheus M, Devins T, Johansen OE, Woerle HJ, et al; EMPA-REG OUTCOME Investigators: Empagliflozin, cardiovascular outcomes, and mortality in type 2 diabetes. N Engl J Med 373: 2117-2128, 2015.

5. Go AS, Mozaffarian D, Roger VL, Benjamin EJ, Berry JD, Borden WB, Bravata DM, Dai S, Ford ES, Fox CS, et al; American Heart Association Statistics Committee and Stroke Statistics Subcommittee: Executive summary: heart disease and stroke statistics - 2013 update: a report from the American Heart Association. Circulation 127: 143-152, 2013.

6. Low Wang CC, Hess CN, Hiatt WR and Goldfine AB: Clinical update: Cardiovascular disease in diabetes mellitus: Atherosclerotic cardiovascular disease and heart failure in type 2 diabetes mellitus - mechanisms, management, and clinical considerations. Circulation 133: 2459-2502, 2016.

7. Nauck MA, Kleine N, Orskov C, Holst JJ, Willms B and Creutzfeldt W: Normalization of fasting hyperglycaemia by exogenous glucagon-like peptide 1 (7-36 amide) in type 2 (non-insulin-dependent) diabetic patients. Diabetologia 36: 741-744, 1993.

8. Drucker DJ and Nauck MA: The incretin system: Glucagon-like peptide- 1 receptor agonists and dipeptidyl peptidase- 4 inhibitors in type 2 diabetes. Lancet 368: 1696-1705, 2006.

9. Basu S, Yoffe P, Hills N and Lustig RH: The relationship of sugar to population-level diabetes prevalence: an econometric analysis of repeated cross-sectional data. PLoS One 8: e57873, 2013.

10. Ha KH and Kim DJ: Trends in the Diabetes Epidemic in Korea. Endocrinol Metab (Seoul) 30: 142-146, 2015.

11. Monami M, Adalsteinsson JE, Desideri CM, Ragghianti B, Dicembrini I and Mannucci E: Fasting and post-prandial glucose and diabetic complication. A meta-analysis. Nutr Metab Cardiovasc Dis 23: 591-598, 2013.

12. Fowler MJ: Microvascular and macrovascular complications of diabetes. Clin Diabetes 26: 77-82, 2008.

13. Malik VS, Popkin BM, Bray GA, Després JP and Hu FB: Sugar-sweetened beverages, obesity, type 2 diabetes mellitus, and cardiovascular disease risk. Circulation 121: 1356-1364, 2010.

14. Zhang Y, Hu G, Yuan Z and Chen L: Glycosylated hemoglobin in relationship to cardiovascular outcomes and death in patients with type 2 diabetes: A systematic review and meta-analysis. PLoS One 7: e42551, 2012. 
15. Gaster B and Hirsch IB: The effects of improved glycemic control on complications in type 2 diabetes. Arch Intern Med 158: 134-140, 1998.

16. UK Prospective Diabetes Study (UKPDS) Group: Intensive blood-glucose control with sulphonylureas or insulin compared with conventional treatment and risk of complications in patients with type 2 diabetes (UKPDS 33). Lancet 352: 837-853, 1998.

17. Shichiri M, Kishikawa H, Ohkubo Y and Wake N: Long-term results of the Kumamoto Study on optimal diabetes control in type 2 diabetic patients. Diabetes Care 23 (Suppl 2): B21-B29, 2000
18. Nadkarni P, Chepurny OG and Holz GG: Regulation of glucose homeostasis by GLP-1. Prog Mol Biol Transl Sci 121: 23-65, 2014.

19. Seino S, Shibasaki T and Minami K: Dynamics of insulin secretion and the clinical implications for obesity and diabetes. J Clin Invest 121: 2118-2125, 2011.

20. Gaisano HY, Macdonald PE and Vranic M: Glucagon secretion and signaling in the development of diabetes. Front Physiol 3: 349, 2012.

21. Than NN and Newsome PN: A concise review of non-alcoholic fatty liver disease. Atherosclerosis 239: 192-202, 2015. 